\title{
Iatrogenic Tracheal Stenosis Presenting as Persistent Asthma
}

\author{
Timothy J Barreiro DO, Christian Ghattas MD, and Cherry Ann Valino MD
}

\begin{abstract}
Although the incidence of post-intubation tracheal stenosis has markedly decreased with the advent of large volume, low pressure endotracheal tube cuffs, it still occurs, commonly in patients after prolonged intubation. We report a case of tracheal stenosis that developed after a brief period of endotracheal intubation, and that was misdiagnosed and treated as asthma and panic attacks. Key words: asthma; tracheal stenosis; wheezing; airway disease; interventional bronchoscopy. [Respir Care 2013;58(9):e107-e110. (C) 2013 Daedalus Enterprises]
\end{abstract}

\section{Introduction}

Tracheal stenosis is a common complication of tracheostomy, as well as endotracheal intubation. In recent years the incidence of post-intubation tracheal stenosis has markedly decreased with the advent of large volume, low pressure endotracheal tube cuffs, but tracheal stenosis still affects patients requiring prolonged intubation. ${ }^{1}$ We report a case of tracheal stenosis that developed after a brief period of endotracheal intubation, and that was misdiagnosed and treated as asthma and panic attacks.

\section{Case Report}

A 30-year-old, lifelong non-smoker was evaluated in the emergency room after his fourth visit to the hospital for symptoms of dyspnea, wheezing, and chest tightness. His medical history was notable for panic attacks and intubation for 48 hours after a bout of pneumonia 8 months earlier. He denied a history of asthma, but reported environmental, feline, pollen, and cephalosporin allergies. His

The authors are affiliated with Department of Internal Medicine, St Elizabeth Health Center, Youngstown, Ohio. Dr Barreiro is also affiliated with the Ohio University Heritage College of Osteopathic Medicine, Athens, Ohio, and with the Northeast Ohio Medical University, Rootstown, Ohio.

The authors have disclosed no conflicts of interest.

Correspondence: Timothy J Barreiro DO, Department of Internal Medicine, St Elizabeth Health Center, 1044 Belmont Avenue, Youngstown OH 44501. E-mail: tbarreir@neomed.edu.

DOI: $10.4187 /$ respcare.02231 symptoms included progressively worsening exertional dyspnea over the past month. He also reported heart palpitations and episodic non-productive cough. At each previous emergency room visit he was given albuterol and discharged on oral prednisone without symptom relief. He was single and unemployed.

On physical examination his temperature was $37^{\circ} \mathrm{C}$, heart rate 88 beats/min, blood pressure $122 / 74 \mathrm{~mm} \mathrm{Hg}$, breathing frequency 18 breaths/min, and $\mathrm{S}_{\mathrm{pO}_{2}} 98 \%$. Auscultation revealed mild bilateral expiratory wheezes and audible breathing from his mouth. Chest radiograph was normal. Computed tomography (CT) angiogram was negative for pulmonary embolism. FVC was $5.12 \mathrm{~L}$ (88\% of predicted), $\mathrm{FEV}_{1}$ was $2.22 \mathrm{~L}$ ( $47 \%$ of predicted), and $\mathrm{FEV}_{1} / \mathrm{FVC}$ was $43 \%$. Static lung volumes were normal. Figure 1 shows his flow-volume loop.

Cervical CT revealed stenosis involving the upper third of the trachea (Fig. 2). Bronchoscopy revealed normal vocal cords. Two centimeters below the vocal cords there was a circumferential stenosis producing $85 \%$ obstruction (Fig. 3). Initiation of dexamethasone and bronchodilators produced minimal symptom improvement. He was referred to a tertiary center for surgery.

\section{Discussion}

Tracheal stenosis is a rare but serious complication of endotracheal intubation. The incidence declined following the introduction of high-volume, low-pressure endotracheal tube cuffs. The reported incidence has varied. In one prospective study, $11 \%$ of patients intubated with high-volume, low-pressure cuffed tubes developed tracheal stenosis, exhibited by $50-90 \%$ narrowing of the tracheal lumen at the cuff site. ${ }^{2}$ Another study reported an incidence of 4.9 


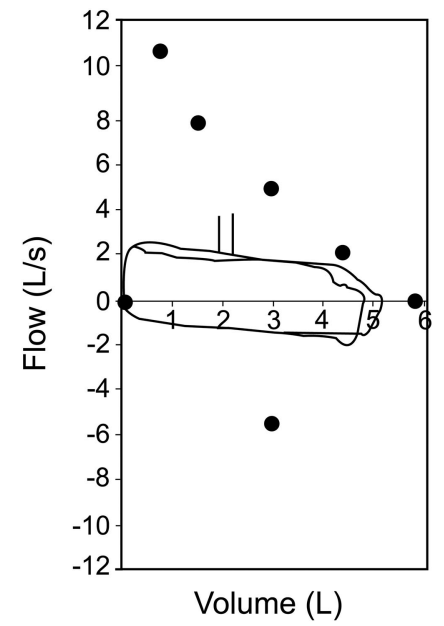

Fig. 1. Flow-volume loop revealing fixed upper-airway obstruction.

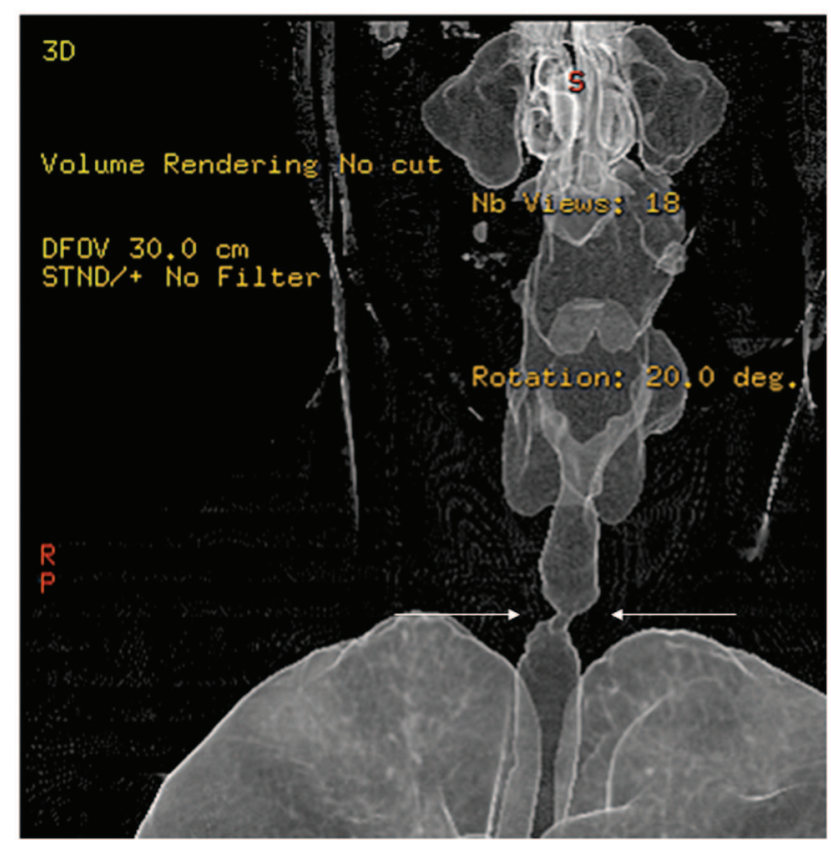

Fig. 2. Three-dimensional computed tomogram shows stenosis of the upper trachea (arrows).

cases per million per year in a general population. ${ }^{3}$ The overall incidence of post-intubation and post-tracheotomy stenosis ranges from $6 \%$ to $22 \%$, but only $1-2 \%$ of the patients are symptomatic or have severe stenosis. ${ }^{1,4}$

The etiology of post-intubation tracheal stenosis is multifactorial. One of the most important causes is cuff pressure that exceeds the mucosal capillary perfusion pressure (20-30 $\mathrm{mm} \mathrm{Hg}$ ). High cuff pressure causes ischemic injury as rapidly as $15 \mathrm{~min}$ after intubation. This ischemia leads to ulceration, chondritis, and, eventually, fibrosis within 3-6 weeks.

Another factor is the duration of intubation. The onset of stenosis usually ranges from 2-24 weeks following ex-
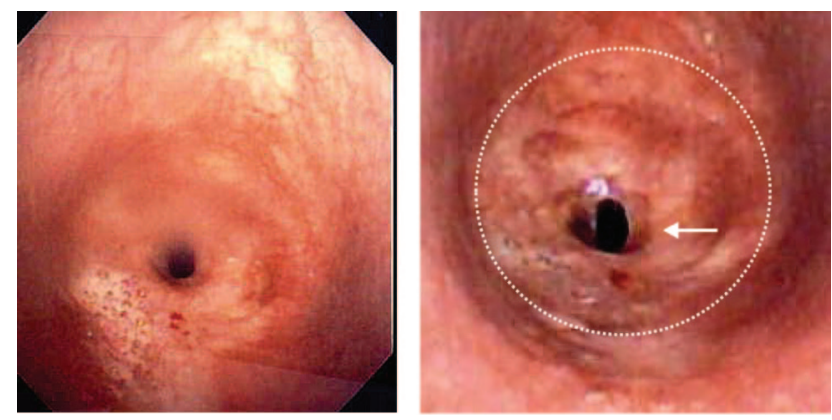

Fig. 3. Left: Bronchoscopy shows circumferential stenosis. Right: The dotted line shows the normal diameter of the trachea. The arrow points to the stenotic ring.

tubation, ${ }^{5}$ but the incidence increases with the duration of intubation, and tracheal stenosis is rare when intubation was $<1$ week. $^{6}$ Whited found a $12 \%$ incidence of laryngeal stenosis in patients who were intubated for $\geq 11$ days, a 5\% incidence following 6-10 days of intubation, and a $2 \%$ incidence with $<6$ days of intubation. ${ }^{7}$ To our knowledge, only 3 cases of post-intubation tracheal stenosis have been reported with intubation of $<48$ hours. One patient developed tracheal stenosis after 10-12 hours of intubation, and the 2 other cases manifested at 24 and 48 hours. ${ }^{8,9}$ Our patient developed post-intubation tracheal stenosis after only 48 hours of intubation, making it extremely rare.

Other factors include endotracheal tube size, hypotension at the time of intubation, high tracheotomy site, traumatic events during intubation, steroid use, advanced age, severe reflux disease, autoimmune diseases, obstructive sleep apnea, and radiation therapy..$^{1,10}$

Most patients who undergo endotracheal intubation develop some degree of stenosis. ${ }^{11}$ However, patients usually remain asymptomatic until stenosis narrows the trachea to approximately $70 \%$ of its original lumen. ${ }^{10}$ In patients with a lesser degree of stenosis, diagnosis is more challenging. These patients may present with recurrent pneumonia or progressive dyspnea on exertion. ${ }^{12}$ Such patients are often misdiagnosed and treated for asthma or chronic bronchitis, as in our patient. ${ }^{10}$ Stridor is not usually seen until the tracheal lumen is $<5 \mathrm{~mm}$, and cyanosis may be a late finding. ${ }^{5}$ The differential diagnosis for tracheal stenosis is usually categorized as focal or diffuse (Table).

Diagnosis is aided by spirometry, bronchoscopy, and reconstructive imaging. The flow-volume loop typically reveals a fixed obstructive pattern, with flattening of the inspiratory and expiratory curves (see Fig. 1). ${ }^{13}$ Bronchoscopy is the diagnostic modality of choice, as it can exclude diseases with similar presentations, such as tracheomalacia and vocal cord paralysis, while at the same time providing therapeutic modalities. While imaging techniques have become faster and allow for anatomic detail, conventional radiography is often the first step in the evaluation of suspected central airway disease, and may be adequate to 
Table. Differential Diagnosis of Tracheal Diseases

\begin{tabular}{l}
\hline \hline Focal Disease \\
Post-intubation stenosis \\
Post-infectious stenosis \\
Post-transplant stenosis \\
Systemic disease \\
Crohn disease \\
Sarcoidosis \\
Behçet disease \\
Diffuse disease \\
Wegener granulomatosis \\
Relapsing polychondritis \\
Tracheobronchopathia osteochondroplastica \\
Amyloidosis \\
Papillomatosis \\
Rhinoscleroma
\end{tabular}

identify abnormalities. However, CT improves both the detection and characterization of central airway disease entities and may show findings such as calcifications that aid in the planning of bronchoscopy or therapy. Furthermore, the 3-dimensional CT we used in our patient is a powerful tool that facilitates therapy selection.

The treatment for tracheal stenosis has changed dramatically over the years ${ }^{14}$ and requires a comprehensive multidisciplinary approach. The primary objective of airway reconstruction in post-intubation tracheal stenosis is to restore a patent airway while minimizing the risk of further iatrogenic injury. Tracheal resection followed by end-toend anastomosis is the standard of care for tracheal stenosis, and has a success rate of up to $97 \% .{ }^{15,16}$

Advances in endoscopic interventions have improved the treatments options for patients with tracheal stenosis. ${ }^{17}$ Minimally invasive treatment, including neodymiumyttrium-aluminum-garnet laser (Nd:YAG) and $\mathrm{CO}_{2}$ laser excision, dilatation, endoscopic stent placement, and topical application of mitomycin $\mathrm{C}$, reduce airway surgical manipulation and post-surgical inflammatory response. ${ }^{18}$ Still, for better outcome, endoscopic management requires early referral for stenotic lesions shorter than $10 \mathrm{~mm}$, or shorter than $30 \mathrm{~mm}$ if stenting is considered, with no circumferential scarring and no loss of cartilagenous support. ${ }^{15,16}$ Balloon dilatation has been well tolerated, but was often followed by recurrence requiring repeated dilatation or surgery. Improvements and advances in endoscopic techniques and topical mitomycin $\mathrm{C}$ have expanded treatment options for tracheal stenosis with excellent outcomes. ${ }^{18}$

While some argue that rigid bronchoscopy remains the therapeutic standard, it is now used less frequently. While tracheal resection and reconstruction have predictable, reliable results, airway stents are now used for both benign and malignant central airway obstruction. Stents fall into 2 major categories: silicone and self-expanding metallic. ${ }^{19}$ Stent selection for tracheal stenosis is based on many factors, including operator comfort. Complications are associated with all types of stents. Smaller studies have reported long-term silicone stenting to be effective in curing post-intubation stenosis in 50\% of patients, with removal of the stent at 1 year. Less than half the patients required any follow-up interventions. Airway obstruction from tracheal stenosis usually involves a very short segment of the trachea and can be circumferential, as in our case, or anterior, depending on etiology (see the Table).

Tracheal stenosis is a serious complication following intubation. In patients with a history of intubation who present with respiratory symptoms, tracheal stenosis should be included in the differential diagnosis.

\section{REFERENCES}

1. Zias N, Chroneou A, Tabba MK, Gonzalez AV, Gray AW, Lamb $\mathrm{CR}$, et al. Post tracheostomy and post intubation tracheal stenosis: report of 31 cases and review of the literature. BMC Pulm Med 2008;8:18.

2. Stauffer JL, Olson DE, Petty TL. Complications and consequences of endotracheal intubation and tracheotomy. A prospective study of 150 critically ill adult patients. Am J Med 1981;70(1):65-76.

3. Nouraei SA, Ma E, Patel A, Howard DJ, Sandhu GS. Estimating the population incidence of adult post-intubation laryngotracheal stenosis. Clin Otolaryngol 2007;32(5):411-412.

4. Nesek-Adam V, Mrsic V, Oberhofer D, Grizelj-Stojcic E, Kosuta D, Rasic Z. Post-intubation long-segment tracheal stenosis of the posterior wall: a case report and review of the literature. J Anesth 2010;24(4):621-625.

5. Majid A, Guerrero J, Gangadharan S, Feller-Kopman D, Boiselle P, DeCamp M, et al. Tracheobronchoplasty for severe tracheobronchomalacia: a prospective outcome analysis. Chest 2008;134(4):801-807.

6. Zarogoulidis P, Kontakiotis T, Tsakiridis K, Karanikas M, Simoglou $\mathrm{C}$, Porpodis $\mathrm{K}$, et al. Difficult airway and difficult intubation in postintubation tracheal stenosis: a case report and literature review. Ther Clin Risk Manag 2012;8:279-286.

7. Whited RE. Laryngeal dysfunction following prolonged intubation. Ann Otol Rhinol Laryngol 1979;88(4 Pt 1):474-478.

8. Yang KL. Tracheal stenosis after a brief intubation. Anesth Analg 1995;80(3):625-627.

9. Bradeer TL, James ML, Sear JW, Searle JF, Stacey R. Tracheal stenosis associated with a low pressure cuffed endotracheal tube. Anaesthesia 1976;31(4):504-507.

10. Papla B, Dyduch G, Frasik W, Olechnowiwz H. Post-intubation tracheal stenosis: morphological-clinical investigations. Pol J Pathol 2003;54(4):261-266.

11. Heffner JE. Timing of tracheotomy in ventilator-dependent patients. Clin Chest Med 1991;12(3):611-625.

12. Allen AM, Abdelrahman N, Silvern D, Fenig E, Fruchter O, Kramer MR. Endobronchial brachytherapy provides excellent long-term control of recurrent granulation tissue after tracheal stenosis. Brachytherapy 2012;11(4):322-326.

13. Gittoes NJ, Miller MR, Daykin J, Sheppard MC, Franklyn JA. Upper airway obstruction in 153 consecutive patients presenting with thyroid enlargement. BMJ 1996;312(7029):484.

14. Brigger MT, Boseley ME. Management of tracheal stenosis. Curr Opin Otolaryngol Head Neck Surg 2012;20(6):491-496. 


\section{Iatrogenic Tracheal Stenosis Presenting as Persistent Asthma}

15. Nouraei SA, Ghufoor K, Patel A, Ferguson T, Howard DJ, Sandhu GS. Outcome of endoscopic treatment of adult postintubation tracheal stenosis. Laryngoscope 2007;117(6):1073-1079.

16. Sarper A, Ayten A, Eser I, Ozbudak O, Demircan A. Tracheal stenosis aftertracheostomy or intubation: review with special regard to cause and management. Tex Heart Inst J 2005;32(2):154-158.

17. Lee SY, Lee SM, Park SR, Chang JW, Chung TS, Choi HS. Successful treatment of tracheal stenosis with slide tracheoplasty after the failure of resection with end-to-end anastomosis. Clin Exp Otorhinolaryngol 2009;2(4):211-214.

18. Melkane AE, Matar NE, Haddad AC, Nassar MN, Almoutran HG, Rohayem Z. Management of postintubation tracheal stenosis: appropriate indications make outcome differences. Respiration 2010;79(5): 395-401.

19. Casal RF. Update in airway stents. Curr Opin Pulm Med 2010;16(4): 321-328. 